\title{
Metalcasting Industry Research
}

AFS is involved in several research partnerships funded through government funding and industry contributions and other means. Support of research is critical for North America to maintain a strong, vibrant, healthy and continually advancing metalcasting industry. AFS participates in these projects by securing industry partners and providing technical management and oversight.

Current research funding partnerships include:

- Advanced Casting Research Center (ACRC), which is part of the Metal Processing Institute (MPI) at Worcester Polytechnic Institute (WPI).

- U.S. Department of Defense (DOD), Defense Logistics Agency (DLA) Castings Solutions for Readiness (CSR)
Program and Innovative Casting Technology (ICT) Program, both funded through the American Metalcasting Consortium (AMC).

- The National Network for Manufacturing Innovation (MANUFACTURING USA) and the four current AFS-involved consortium: (America Makes-National Additive Manufacturing Innovation Institute, Lightweight Innovations For Tomorrow-LIFT which was formerly called Lightweight and Modern Metals Manufacturing Innovation-LM3I, Digital Manufacturing and Design Innovation-DMDI and Clean Energy Smart Manufacturing Innovation Institute-SMLC CESMII).

\section{AFS Funded \& Monitored Research}

AFS directly funds research projects from allocation of a portion of the annual dues paid by AFS Corporate Membership. The current AFS-funded research projects are described below.

\section{Improving Dimensional Accuracy of Castings from Silica Sand Molds}

Coordinators: Sairam Ravi, University of Northern Iowa and the AFS Cured Sand \& Aggregate Committee

The rules of thumb concerning dimensional changes from pattern to final casting are not accurate enough to predict actual casting dimensions. Metalcasters will usually require several trial castings and pattern revisions before they meet the customer's dimensional accuracy requirements. This also causes design engineers to add extra machine stock, which inflates the cost of every cast part produced from silica sand molds and cores. Typical machining for castings may cost as much as five to seven times what the original casting cost. This often makes it more economical to produce machined parts from rolled alloy rather than castings. Computer simulations that predict final casting dimensions based on the properties of the molding aggregates can help in solving this issue while providing sustainability to silica sand molding.

Objectives are to validate existing dimensional accuracy code through simulation and measurement of production parts, refine codes as needed to match non-constrained core conditions, determine high-temperature retrained strength of PUCB and PUNB cores and adjust code to compensate for casting solidification constraints, and conduct foundry validation trials in iron for constrained casting dimensions.
The research is being conducted at University of Northern Iowa (UNI) and is co-funded by the New Generation Sand Consortium (NGS). The research has been completed, and the final report will be ready for distribution soon.

\section{Influence of Core Variables in Semipermanent Mold Dimensions}

Coordinators: Dr. Paul Sanders, Michigan Technological University and AFS Permanent Mold Practices Committee

Casting shape, core materials (sands and resins) and the methods used to make and remove sand cores will influence the final dimensional shape and repeatability of a semipermanent mold casting. Rather than understanding or predicting the dimensional variance in a casting, a common practice has been to allow sufficient tolerance in the design to accommodate the unknowns. Foundry and design engineers often rely on "rules of thumb," previous experience with similar parts or a hopefully understanding customer who will change the drawing to accommodate the actual result of the initial runs.

The "rule of thumb" for permanent mold castings is to use .006 inches $/$ inch $(\mathrm{mms} / \mathrm{mm})$ shrinkage factor for tooling construction. Actual instances of .003 to .010 shrink factors have been observed. The shrink factor used on the sand core is typically built to $.010 \mathrm{in} /$ in with instances from .008 to .013 observed in practice. These various process and tooling 
variables often lead into initial tooling questions that have lots of anecdotal-based opinions in the industry and little published data.

Objectives are: make cold box and shell cores using multiple resin levels, dimensionally scan cores and analyze data, pour castings and analyze the cast part to establish a deviation from the perfect shape map. The project will evaluate the significance of experimental factors such as core type, resin level, knockout time and dimensional metrics, and assess metal shrinkage, core deflections, and resultant residual stresses and strains. The goal is to develop physical calculations to predict dimensional changes and develop guidelines for shrinkage factor as a function of process variables.

The work is being monitored by AFS Permanent Mold Practices Committee. Those interested in more information about the project or how to participate should contact the PI Paul Sanders at sanders@mtu.edu or the AFS Technical Department (technicalassistant@afsinc.org).

\section{Prediction and Control of Distortion in Permanent Molds}

Coordinators: Dr. David Schwam, Case Western Reserve University (CWRU) and AFS Permanent Mold Committee

Permanent molds are subjected to high thermal stresses and are prone to distortion. Each casting cycle introduces heat into local areas of the mold, increasing the temperature and creating severe thermal gradients. Most of the mold material stays in the elastic deformation region and returns to the original dimensions upon cooling. However, in some parts of the mold the compressive surface stresses may exceed yield, resulting in permanent, plastic deformation. Other metallurgical events are also in play as the mold distortion occurs over many casting cycles where time at temperature is an issue.

This is primarily a computational effort supported by experimental data. In this study, finite element modeling will be used to identify the sources of mold distortion and also to explore methods to minimize mold distortion. Computer software will be used to assess both thermal stress and the change in microstructure that will occur due to time and temperature for the hot face of the mold cavity.

A permanent mold will be obtained from participating companies along with the CAD used to fabricate it. The geometry of the used mold will be captured with a laser scanner (CWRU). Computer simulations of stress and distortion will be conducted by Dante Solutions to identify sources of mold distortion, and predictions for the specific mold will be compared to the laser-scanned model.

This project is being monitored by the AFS Permanent Mold Practices Committee. Those wishing more information about the project or how to participate should contact the AFS Technical Department (technicalassistant@afsinc.org).

\section{Prefiring Time/Temperature Effect on Investment Shells Thermo-Mechanical Properties}

Coordinators: Dr. Mingzhi Xu, Missouri University of Science \& Technology, and AFS Investment Casting Committee

Investment shells are typically prefired before being poured. In the steel industry, the prefiring temperature is generally high enough to trigger some amount of devitrification of the amorphous silica constituent in the shell molds. Different foundries have their own prefiring temperature/time profiles which result in different amount of devitrification, thus affecting the thermo-mechanical properties of the shell molds. Estimating thermal properties from handbook data without considering the phase changes during the process is usually inaccurate. Applying thermal property values from commonly used simulation software database without carefully considering the difference of prefiring regime will often not represent the reality.

The ultimate objective of this project is to come up with a kinetic model that predicts the thermo-mechanical properties of silica-based investment shells.

The work is being monitored by AFS Investment Casting Committee. Those wishing more information about the project or how to participate should contact the PI Mingzhi Xu at mxu@mst.edu or the AFS Technical Department (technicalassistant@afsinc.org).

\section{Air Sampling Method for OSHA Silica Compliance}

Coordinators: Robert Scholz, TRC Environmental, and AFS EHS Committee

OSHA's new worker exposure standard for respirable, crystalline silica requires that foundries limit exposure during work shifts to about one-half the concentration level of the previous Permissible Exposure Limit (PEL). Meeting this strict standard will necessitate that foundries refine their ability to identify and address root causes of exposure. Unfortunately, the method of averaging silica exposure over the work shift does not provide a basis for pinpointing those activities that have the greatest impact on overall average exposure levels. Real-time monitoring of silica concentrations could provide the needed diagnostic capability. However, this method is only in the developmental stage at this time. Instruments are commercially available to measure the concentration of silicabearing respirable particulate matter (RPM). If real-time RPM measurements can be correlated to its silica content in a 
foundry situation, the needed capability for diagnosing the root causes of exposure could be made available to foundries. The goal of the project emanating from this proposal is to develop a procedure for providing the needed correlation in a wide variety of foundry process operations.

The work is being monitored by AFS Environmental Health and Safety Committee. For more information, contact the PI Robert Scholz at rscholz@trcsolutions.com or the AFS Technical Department (technicalassistant@afsinc.org).

\section{Quantify Casting Quality Through Filling Conditions}

Coordinators: Dan Hoefert, Eck Industries, and AFS Aluminum and Light Metals Committee

Today, predicting the actual filling damage that oxides may cause to a casting remains largely based on theory, experience and speculation. In the past decade, great strides have been made in simulation capabilities. Heat transfer data and computational fluid flow have been combined to do a wonderful job of predicting porosity and mechanical properties. Filling concerns such as excessive filling velocity, eddies and other turbulent conditions can also be noted with simulation software. However, simulation software does not take the chemical reaction of oxide formation into account. Filling results only offer an indirect indication of the potential oxide damage, with no effect to the predicted porosity or mechanical results. As such, serious pitfalls can exist when it comes to interpreting simulation results.

Without correlating filling concerns related to oxide damage, misleading simulation results can be predicted. If a gating design includes well-placed feeders and chills, but includes turbulent filling conditions, simulation can falsely predict excellent soundness and mechanical properties, despite the filling damage noted indirectly by viewing the filling results. As foundries look for competitive ways to tool and fill castings, this confusion can tempt a foundry to choose a more turbulent-fill gating design if the simulation results predict quality advantages over a more tranquil-fill gating design. This project is intended to help answer these difficult questions with meaningful data that can be used to quantify these concerns.

The project is being monitored by AFS Aluminum \& Light Metals Division. Those wishing more information about the project can contact the PI Dan Hoefert at Dan.Hoefert@eckindustries.com or the AFS Technical Department (technicalassistant@afsinc.org).

\section{Evaluation of Alternative Aggregates for Use in Green Sand Systems}

Coordinator: Jerry Thiel, University of Northern Iowa
The lower cost of silica sand and its relatively high refractoriness makes it a viable and economical choice for green sand systems, with millions of tons of silica sand used every year. However, a new rule by Occupational Safety and Health Administration (OSHA) considerably toughens the use of silica sand in a foundry. The regulation will require foundries to implement extensive engineering controls, which will be cost prohibitive for small-to-medium-sized metalcasting facilities. One possible solution for foundries will be to utilize a non-silica aggregate in their green sand systems. This will minimize or eliminate the respirable crystalline silica, in addition to the large capital cost associated with engineering controls mandated in the new regulations. Little research has been conducted in the use of alternate non-silica aggregates in a green sand system, and these materials need to be characterized and tested for ensuring good results when bonded with a bentonite clay.

It is the intent of the project to determine what limitations non-silica aggregates have in the replacement of silica sand and then to educate the industry in these areas. The work is being monitored by AFS Technical Department. Anyone interested in more information about the project should contact the PI Jerry Thiel at thiel@uni.edu or the AFS Technical Department (technicalassistant@afsinc.org). The research will be completed later in 2018.

\section{Alternative Granular Media for Green Sand Casting}

Coordinators: Dr. Sam Ramrattan, Western Michigan University

The new Occupational Safety and Health Administration (OSHA) regulations limiting exposure to respirable crystalline silica has renewed interest in alternatives to silica sand which can withstand the heat of metalcasting and the rigors of repetitive reuse. Foundries have used alternative materials for decades. Chromite, zircon, olivine and carbon sands have each been successfully used to solve operating problems and thus have developed their specific niches in the foundry materials inventory. However, there are several other materials that are candidates for replacing silica sand, such as fused alumina, sintered bauxite and ceramic sands. Compositions and shapes could be readily tailored for a metal casting process with overall recycling (reclamation) affording sustainable materials management.

This study examines materials that are readily available as alternatives to silica sand from a functionality perspective and evaluate their effectiveness for green sand casting.

Status Update: The work is being monitored by AFS Technical Department. Anyone interested in more information can contact the PI Dr. Sam Ramrattan at sam.ramrattan@wmich.edu or AFS Technical Department (technicalassistant@afsinc.org). The research is completed, and final reports are being written and will be ready for publication soon. 


\title{
Metalcasting Industry Funded \& Monitored Research
}

\author{
American Metalcasting Consortium/Defense \\ Logistics Agency Funded Projects
}

\section{Innovative Casting Technology (ICT) Program}

AFS, as part of the AMC, has secured a contract funded through the U.S. Department of Defense, Defense Logistics Agency, Defense Supply Center Philadelphia and the Defense Logistics Agency (DLA), Ft. Belvoir, VA. The group of projects is under an AMC program entitled Innovative Casting Technology. Two new projects are starting in 2018.

\section{Casting Alloy Data Search (CADS)}

AFS through AMC/DLA has developed a very effective webbased tool called Casting Alloy Data Search (CADS) for the design engineers and ICME professionals, which has been used for over five years by the foundry industry and accessible through their website. CADS needs to further expand to accommodate more ICME relevant data generation for optimization and more accurate predictions, such as thermophysical and thermo-mechanical properties required for process simulation, beyond casting alloys, for example molding materials. The goal of this research project is to enhance the current CADS and create an additional module of CADS for the nonmetallics, such as molding and core materials being used in the sand casting process and populate by generating and validating data useful to the ICME professionals.

CADS is developed in partnership with Product Development \& Analysis (PDA).

\section{Integration of ICME Tools in Casting Design and Process Optimization for Intelligent Manufacturing}

The project will develop an effective and integrated ICME framework as an approach to make more efficient casting designs and improved manufacturing approaches. Current physics-based simulation tools are limited to simulate for a few, finite known process variabilities, but do not account for many more process variables, including dimensional, compositional and section thickness variability inherent to the metal casting process. A comprehensive approach of physics-based simulation with probabilistic meta-modeling using historic data is unique and will allow for rapid and more accurate predictions.

\section{Manufacturing USA: National Network for Manufacturing Innovation}

\section{Manufacturing USA}

The National Network for Manufacturing Innovation has a public name: Manufacturing USA. A total of fourteen manufacturing innovation institutes have been established with AFS involvement with four. These manufacturing institutes are public-private partnerships that each have distinct technology focus areas but work toward a common goal to secure the future of manufacturing in the USA through innovation, education and collaboration. Through Manufacturing USA, industry, academia and government partners are leveraging existing resources, collaborating and co-investing to nurture manufacturing innovation and accelerate commercialization. Each institute is designed to be a public-private organization that provides vision, leadership and resources to its members.

\author{
America Makes-National Additive \\ Manufacturing Innovation Institute
}

America Makes is the National Additive Manufacturing Innovation Institute. As the national accelerator for additive manufacturing (AM) and 3D printing (3DP), America Makes is the nation's leading and collaborative partner in AM and 3DP technology research, discovery, creation and innovation. Structured as a public-private partnership with member organizations from industry, academia, government, nongovernment agencies, and workforce and economic development resources, its mission is to innovate and accelerate AM and 3DP to increase our nation's global manufacturing competitiveness. AFS is partnering with Youngstown Business Incubator (YBI) who has been named a recipient of funds 
from America Makes for the research project "Accelerated Adoption of AM Technology in the American Foundry Industry.” Along with YBI, Youngstown State University (YSU), ExOne, Humtown Products, and the University of Northern Iowa (UNI), the project team for "Accelerated Adoption of AM Technology in the American Foundry Industry” will support the transition of binder jet AM to the small business casting industry by allowing increased access to the use of binder jet equipment and the development of design guidelines and process specifications.

The first AFS ad hoc division on Additive Manufacturing has just gained approval to operate as its own division. The Additive Manufacturing division has three committees: 3D Sand Printing; 3D Hard Tooling; and 3D Investment Cast Tooling.

The second AFS Additive Manufacturing for Metalcasting conference is scheduled for September 10-13, 2018, in Louisville, KY.

\section{Lightweight Innovations for Tomorrow- LIFT}

The Lightweight and Modern Metals Manufacturing Innovation-LM3I-has been renamed LIFT (Lightweight Innovations for Tomorrow) and is headquartered in downtown Detroit. LIFT is led by Ohio-based EWI (Edison Welding Institute), a company that develops and applies manufacturing technology innovation within the manufacturing industry. AFS is part of a 60 -member consortium that will pair leading aluminum, titanium and high-strength steel manufacturers with universities and laboratories pioneering new technology development and research. "The long-term goal of the LIFT LM3I Institute will be to expand the market for and create new consumers of products and systems that utilize new, lightweight, high performing metals and alloys by removing technological barriers to their manufacture, the White House said. The Institute will seek to achieve this through leadership in pre-competitive advanced research and partnerships across defense, aerospace, automotive, energy, and consumer products industries. The White House noted that lightweight and modern metals are utilized in a vast array of commercial products, from automobiles, to machinery and equipment, to marine craft and aircraft. "These ultra-light and ultra-strong materials improve the performance, enhance the safety, and boost the energy and fuel efficiency of vehicles and machines, the White House said. The Institute will advance the state of processing and fabrication technologies for lightweight and modern metals by facilitating the transition between basic/ early research and full-scale production of associated materials, components and systems. AFS will champion the role of the metalcasting industry as a key metals manufacturing sector in this effort, with two initial projects being started in the casting area, one on thin-walled ferrous and the other on thin-walled nonferrous castings. The thin-walled ferrous project is near completion.

\section{Digital Manufacturing and Design Innovation-DMDI}

The idea behind the Institute is that manufacturing is being transformed by digital design, which replaces the draftsman's table with the capacity to work and create in a virtual environment. AFS feels the establishment of a Digital Manufacturing and Design Innovation (DMDI) Institute will increase the successful transition of digital manufacturing and innovative design technologies through advanced manufacturing, create an adaptive workforce capable of meeting industry needs, further increasing domestic competitiveness, and meet participating defense and civilian agency requirements. This project will benefit the U.S. manufacturing industry by providing resource, focal point and network for resolving technical barriers currently limiting the application and integration of digital manufacturing and innovative design technologies. As it relates to the metalcasting industry, the use of these technologies will assist in the more rapid development and production of lighter weight metal cast components for military, energy, transportation and commercial applications. This can allow for design innovation via part consolidation and near-net-shape capabilities of metalcasting, the weight reduction potential of such materials as magnesium, aluminum, titanium and next-generation ferrous metals, and the improved quality and productivity of advanced casting processes; this unique program can make significant strides toward production of high-integrity, complex cast components and advance our manufacturing base. The Institute will also be a resource for training our workforce from manual labor to more highly skilled and technical jobs.

\section{Clean Energy Smart Manufacturing Innovation Institute (CESMII)}

The Smart Manufacturing Leadership Coalition (SMLC) has been selected to lead the new Clean Energy Smart Manufacturing Innovation Institute (CESMII) in partnership with the Department of Energy. The winning coalition, headquartered in Los Angeles, California, brings together a consortium of nearly 200 partners (one of which is AFS) from across academia, industry and nonprofits. The emphasis will be on smart sensors and digital process controls to improve efficiencies in US advanced manufacturing processes. On February 22-23, 2017, SMLC launched, in partnership with DOE, Clean Energy Smart Manufacturing Innovation Institute (CESMII). CESMII is a national network of Regional Manufacturing Centers (RMCs) each focused on local relationships with opportunities for national impact in the areas of technology transfer and workforce development. The power of the network is cross-linking resources, capabilities and expertise 
across business, workforce and technical focus areas, leveraging each region's unique industrial environments. The regions include the California, Gulf coast, Southeast, Northeast, Midwest and Northwest.

\section{AFS Information Services}

\section{Casting Process and Alloy Assistance}

The AFS website aids casting design engineers in selecting the best casting process for a potential component and also provides casting alloy property data on many commonly used alloys. The website provides casting users, design engineers, and purchasers with relevant and accurate information on casting capabilities and properties, providing easily accessible and retrievable information from a single site. The alloy data can be quickly exported to a spreadsheet or FEA tools. The Alloy Database is located on the AFS website, www.afsinc.org, under the "Designers \& Buyers" tab or can be accessed directly at www.metalcastingvirtuallibrary.com/cads/cads.aspx. For more information, contact Steve Robison, AFS Chief Technical Services Officer, at 847-824-0181 ext. 227, or srobison@afsinc.org.

\section{Casting Source Directory}

The Casting Source Directory, is also available to the public on the AFS website. The site provides a directory of North American metalcasters in a single source. Potential casting buyers can search by metal, alloy, casting process, casting size (weight), and U.S. state to locate a casting provider that meets their needs. The Casting Source Directory is located on the AFS website under the "Designers \& Buyers" tab or can be accessed directly at https://www.afsinc.org/metalcasterdirectory. For more information, contact Steve Robison, AFS Chief Technical Services Officer, at 847-824-0181 ext. 227, or srobison@afsinc.org.

\section{CastingConnection}

CastingConnection is a private, professional social network to connect, engage and share critical industry information and best practices in real time. Through the Open Forum and sites devoted to our special interest groups, members gather to network via a comprehensive member directory, participate in focused discussion groups and access and share useful, informative documents and media in all formats. Visit https://castingconnection.afsinc.org.

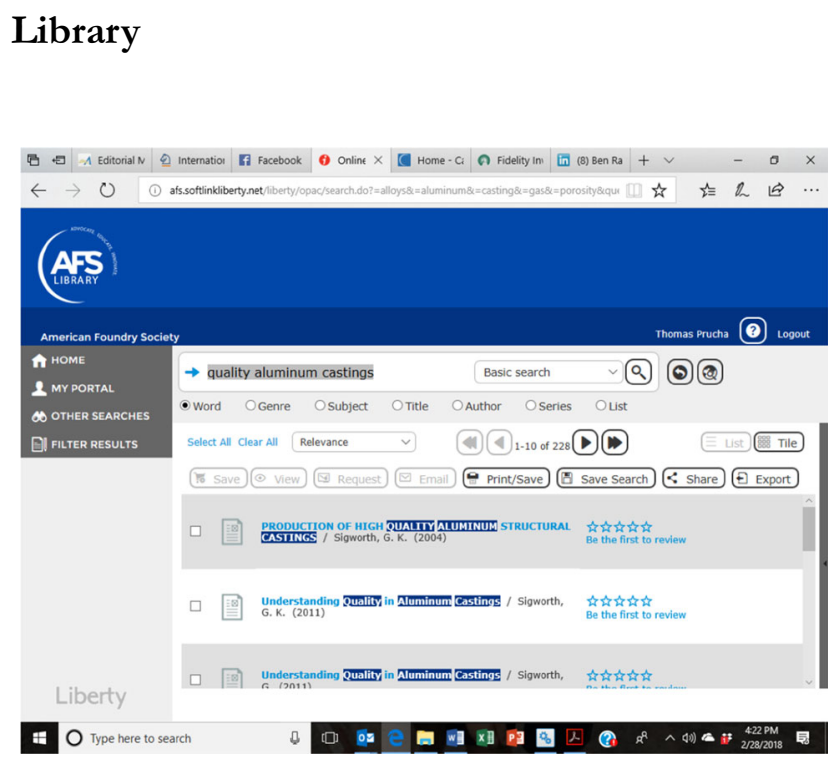

The new AFS online library database serves the needs of the metalcasting industry for current and historic metalcasting information. AFS is continuing to electronically archive the full AFS Transactions series using nondestructive scanning technologies. The project is nearing completion, with many AFS Transactions fully electronically archived and web searchable, from the very first edition (published in 1896) to the present. Located on the AFS website at www.afsinc.org under the "Innovation \& Management" tab, you will find the AFS Library website that houses a large collection of metalcasting reference material. For more information, contact the AFS technical assistant at 847-824-0181 ext. 246, or technicalassistant@afsinc.org. 


\section{e-Learning}

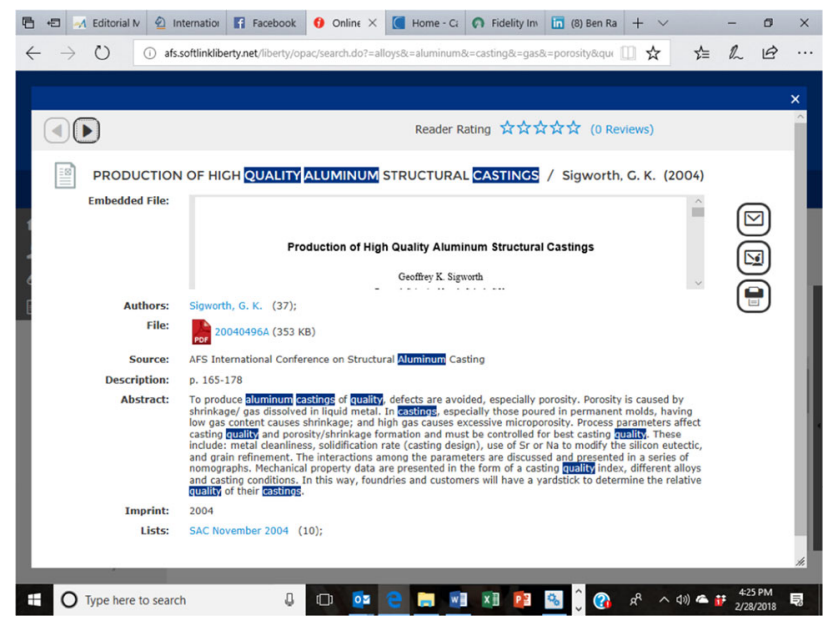

AFS has launched a new program that offers industry-specific training, information and education for metalcasters in a webbased format for a single access fee. The e-Learning program gives subscribing organizations full access to online modules for formal staff training on a wide variety of metalcasting topics. Individual e-Learning modules also are available a la carte. More information and a video demonstration are available at www.afsinc.org/e-learning.

\section{AFS Technology Transfer}

\section{2nd AFS Metalcasting Congress}

Global metalcasters from North America and other markets had positive responses to the 122nd Metalcasting Congress, April 3-5, 2018, in Fort Worth, Texas. The event featured more than 200 exhibits, keynote presentations, technical and management presentations, and AFS Institute courses. The education sessions provided casting personnel opportunities for personal and professional development through 3 days of practical advice, the latest technology advancements, new process and material developments, and foundry case studies. Education sessions covered cast metals and processes, as well as business and management-related issues. The AFS Hub was a dedicated area on the show floor for connecting with AFS staff and other attendees. The HUB featured the AFS Bookstore, The AFS Institute and Member Services, a Makerspace and the Casting of the Year Display. For more information on Congress, contact Metalcasting Congress coordinator Pam Lassila at 847-824-0181 x 240, or plassila@afsinc.org.

\section{Conferences and Workshops}

AFS is hosting a series of webinars to help foundries move toward compliance with the upcoming new regulations on respirable silica exposure. The webinars will cover many issues relating to compliance with the new standard, including alternate non-silica molding media, silica testing, medical testing, and other issues. AFS has also scheduled monthly "members-only" webinars covering a wide range of technical issues to bring the latest technological developments to member. For more information, contact the AFS technical assistant, 847/824-0181 x 246, technicalassistant@afsinc.org, or visit the AFS website at www.afsinc.org.

AFS is offered an extended program of educational opportunities covering all aspects of metalcasting including aluminum casting, iron casting, EHS issues, additive manufacturing, government issues and marketing. These educational events are scheduled to provide relevant and practical information to improve productivity and profitability for metalcasting facilities. The list below shows the complete schedule for AFS technical and management education events, listing of upcoming AFS events. For more information, contact the AFS technical assistant, 847/824-0181 x 246, technicalassistant@afsinc.org, or Chief Technical Services Officer, Steve Robison at 800-537-4237 x 227, stever@afsinc.org.

- August 20-21, 2018; AFS Cast Iron Inoculation Conference, Louisville, KY

- September 10-13, 2018; AFS Additive Manufacturing for Metalcasting, Louisville, $\mathrm{KY}$

- September 16-18, 2018; AFS Foundry Leadership Conference, Amelia Island, FL

- October 7-8, 2018; AFS Advanced Air Seminar, Warrensville Heights, OH

- October 9-11, 2018; AFS 30th EHS Conference, Warrensville Heights, $\mathrm{OH}$

- October 10, 2018; Advanced Cupola Concepts Seminar, Coschocton, $\mathrm{OH}$

- November 5-7, 2018; AFS 2018 Aluminum Casting Conference, Knoxville, TN

- December 11-12, 2018; AFS Marketing Conference, Rosemont, IL 
2018

\section{Metalcasting Industry Calendar of Events}

June $27-28$

July 24

Aug 13-14

Aug 15-16

Aug 20-21

Sept 10-13

Sept 16-18

Sept 23-27

Oct 7-8

Oct $9-11$

Oct 10

Oct 15-17

Oct $15-17$

Oct 21-24

Oct 23-26

Oct 24-26

Nov 5-7

Nov 14-17

Nov 15-16

Dec 11-12

\section{9}

Apr 27-30

Mar 10-14

Jun 25-29

Oct $30-\mathrm{Nov} 1$
AMC Technology Review, Hilton Garden Inn, Rosemont, IL

Developing an All-Star Team (HR Leaders), Miller Park Baseball Stadium, Milwaukee, WI

AFS Volunteer Training Conference, AFS Headquarters, Schaumburg, IL

AFS Board of Directors Meeting, AFS Headquarters, Schaumburg, IL

AFS Cast Iron Inoculation Conference, Sheraton Louisville Riverside Hotel, Louisville, KY

Additive Manufacturing for Metalcasting, Louisville Marriott Downtown, Louisville, KY

AFS Foundry Leadership Conference, Omni Amelia Island Plantation, Amelia Island, FL

World Foundry Organization (WFO) Congress, Krakow, Poland

AFS Advanced Air Seminar, Cleveland Marriott East, Warrensville Heights, $\mathrm{OH}$

AFS 30 ${ }^{\text {th }}$ Environmental, Health \& Safety Conference, Cleveland Marriott East, Warrensville Heights, $\mathrm{OH}$

Advanced Cupola Concepts Seminar, McWane Ductile and Coshocton Village Inn and Suites, Coschocton, $\mathrm{OH}$

North American Die Casting Association (NADCA) Die Casting Congress \& Exposition, Indiana Convention Center, Indianapolis, IN

Future Leaders of Metalcasting Meeting, Dotson Iron Castings, Mankato, MN

Investment Casting Institute (ICI) $65^{\text {th }}$ Annual Technical Conference \& Expo,

Kansas City Marriott Downtown, Kansas City, MO

$6^{\text {th }}$ Keith Millis Symposium, Sonesta Resort, Hilton Head Island, SC

Fundiexpo 2018, Guadalajara, Mexico

AFS 2018 Aluminum Casting Conference, Crowne Plaza Knoxville, Knoxville, TN

2017 China Foundry Week, Suzhou, China

FEF College Industry Conference, Westin Hotel, Chicago, IL

AFS Marketing Conference, Westin O’Hare, Rosemont, IL

CastExpo '19, Georgia World Congress Center, Atlanta, GA

The Minerals, Metals and Materials Society 148th Annual Meeting \& Exhibition, San Antonio, TX

GIFA, Dusseldorf, Germany

AFS International Ferrous Melting Conference, Sheraton Music City, Nashville, TN 


\section{0}

Feb 23-27

Apr 21-23

Oct $18-21$
The Minerals, Metals and Materials Society 149th Annual Meeting \& Exhibition, San Diego, CA AFS $124^{\text {th }}$ Metalcasting Congress, Huntington Convention Center of Cleveland Cleveland, $\mathrm{OH}$ Investment Casting Institute (ICI) World Conference, Disneyland Hotel, Anaheim, CA

For further information on conferences and meetings, please contact the appropriate organization directly at the phone number shown below. Information is updated frequently on the AFS website www.afsinc.org.

The Aluminum Association Inc.

703-358-2960

American Metalcasting Consortium

843-760-3219

American Society of Mechanical Engineers (ASME)

212-705-7100

American Society for Nondestructive Testing

614-274-6003

American Welding Society

305-443-9353

ASM International

440-338-5151

Casting Industry Suppliers Association

815-226-1527

Contract Manufacturers Association

313-643-7187

Ductile Iron Society

440-665-3686

Fabricators \& Manufacturers Association

815-399-8700

Foundry Educational Foundation (FEF)

847-490-9200

Industrial Minerals Association-North America

202-457-0200

Investment Casting Institute

291-573-9770

Iron Casting Research Institute

614-275-4201

Iron \& Steel Society

412-776-1535

The Minerals, Metals \& Materials Society (TMS)

724-776-9000

National Industrial Sand Association

202-457-0200

National Safety Council

630-285-1121

National Tooling \& Machining Association

$301-248-6200$

Non-Ferrous Founders' Society

847-299-0950

North American Die Casting Association

847-279-0001

Society of Automotive Engineers

412-772-7131

SME

800-733-4763

Steel Founders' Society of America

$815-455-8240$ 


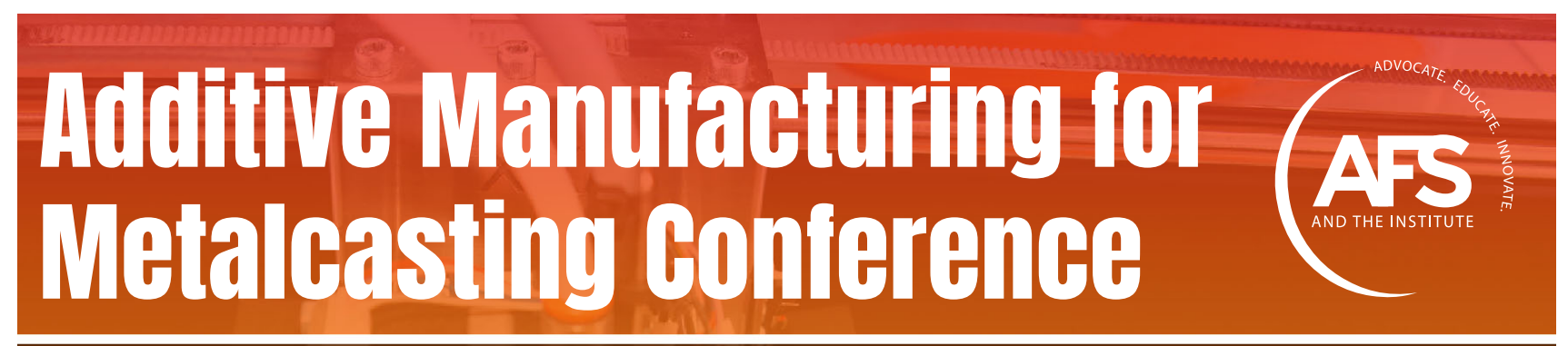

September 10 - 13, 2018 | Louisville Marriott Downtown | Louisville, KY

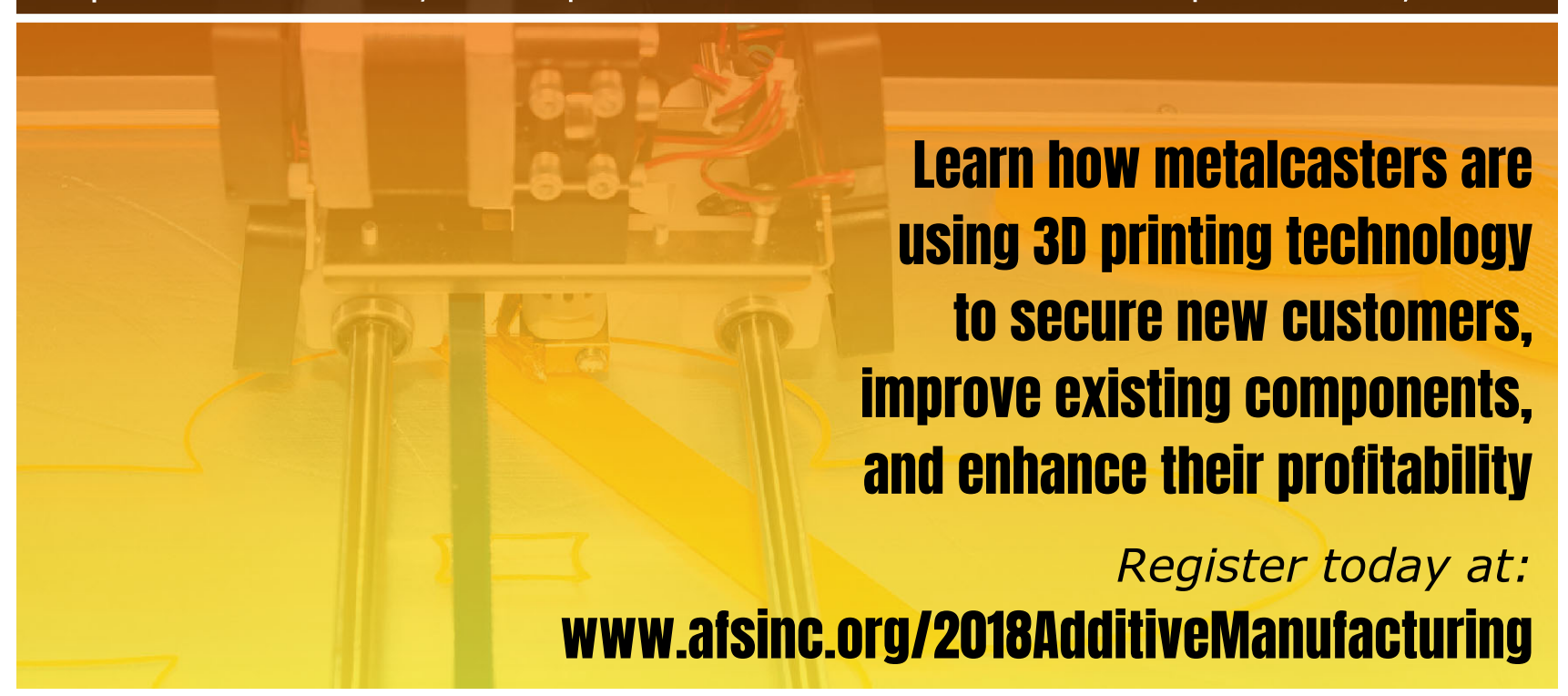




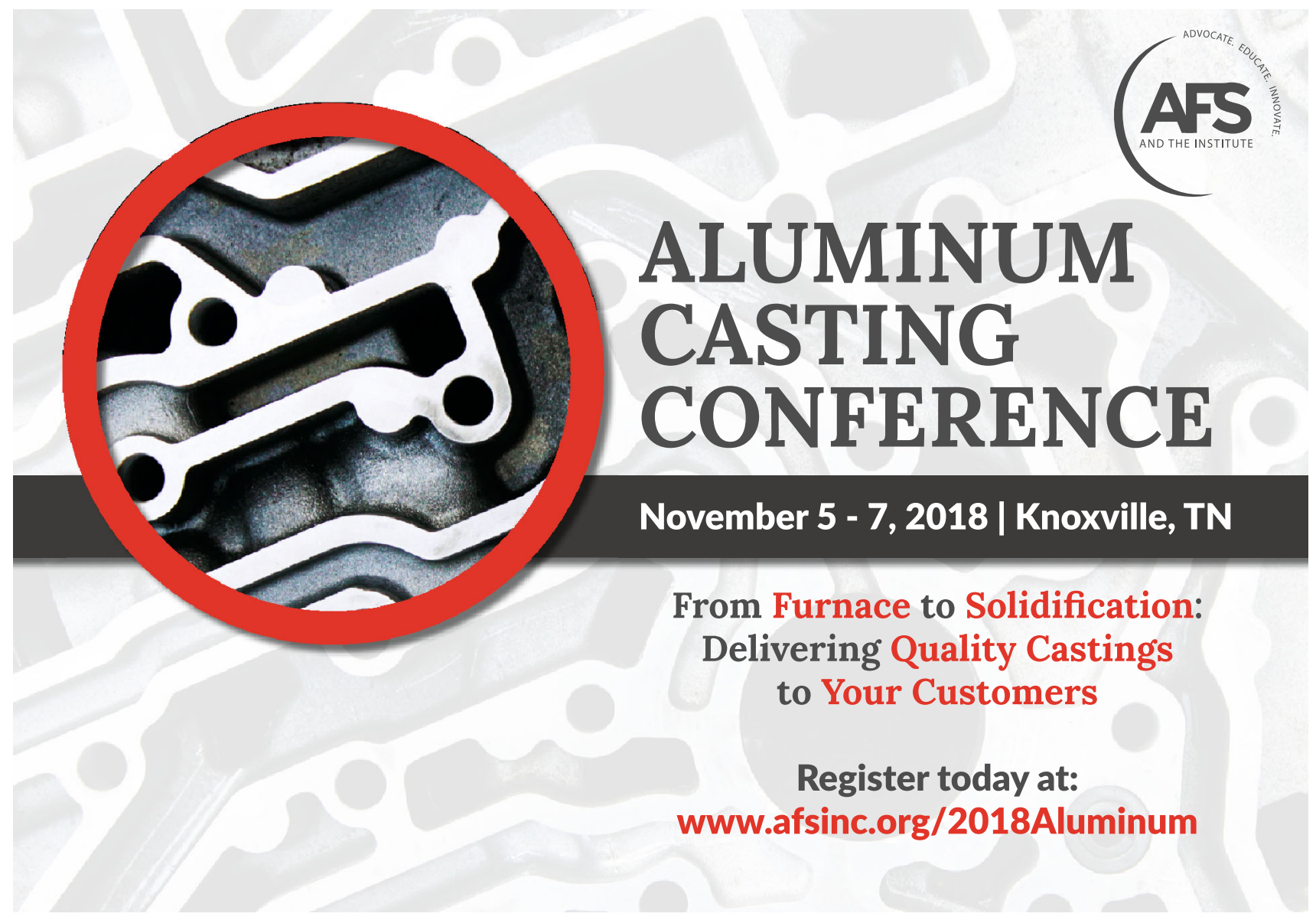



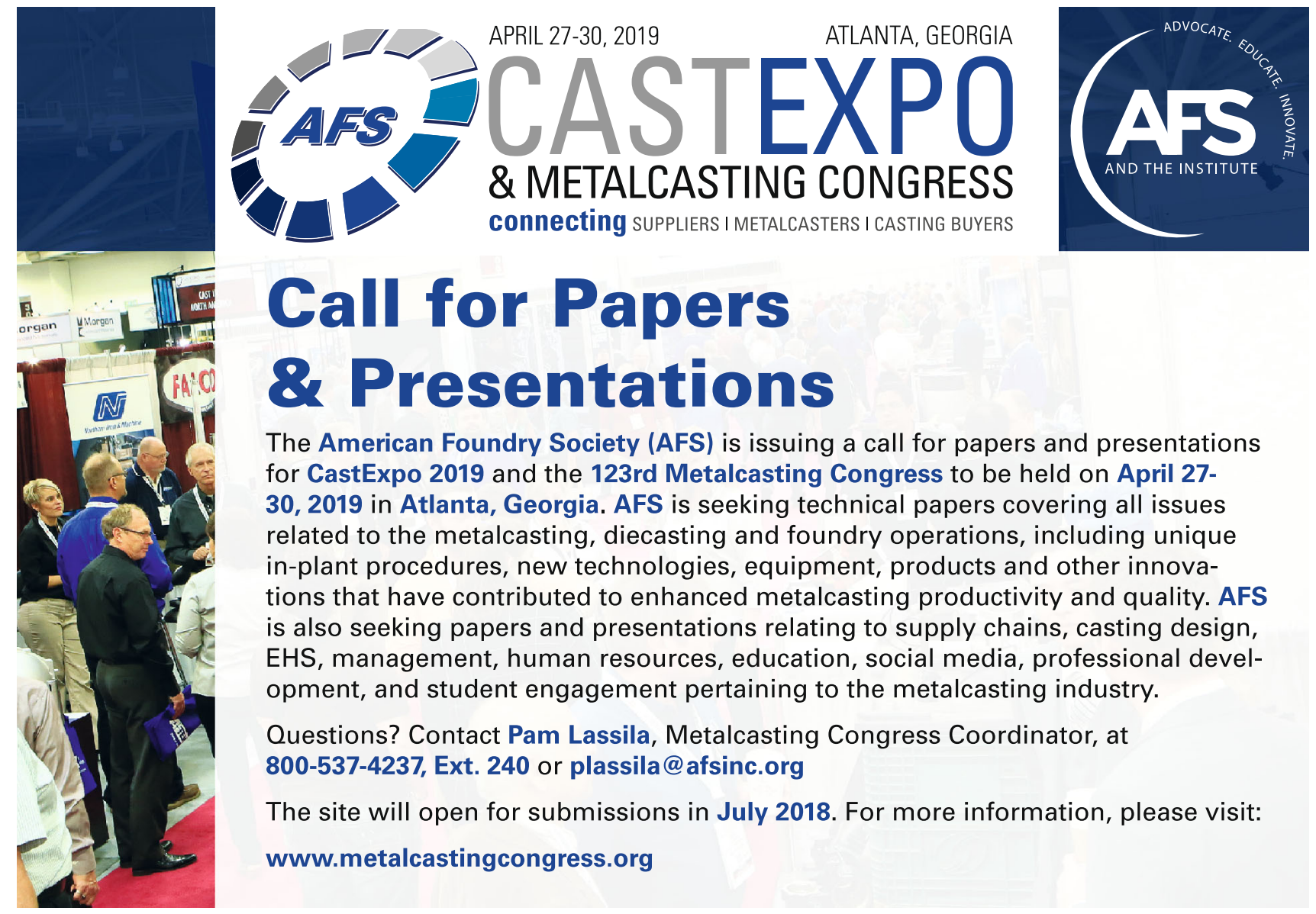

\section{Call for Papers \& Presentations}

The American Foundry Society (AFS) is issuing a call for papers and presentations for CastExpo 2019 and the 123rd Metalcasting Congress to be held on April 2730, 2019 in Atlanta, Georgia. AFS is seeking technical papers covering all issues related to the metalcasting, diecasting and foundry operations, including unique in-plant procedures, new technologies, equipment, products and other innovations that have contributed to enhanced metalcasting productivity and quality. AFS is also seeking papers and presentations relating to supply chains, casting design, EHS, management, human resources, education, social media, professional development, and student engagement pertaining to the metalcasting industry.

Questions? Contact Pam Lassila, Metalcasting Congress Coordinator, at 800-537-4237, Ext. 240 or plassila@ afsinc.org

The site will open for submissions in July 2018. For more information, please visit: www.metalcastingcongress.org 